ISSN: 1410-8917

Jurnal Kimia

-Sains \&

Aplikasi
Jurnal Kimia Sains dan Aplikasi Journal of Scientific and Applied Chemistry

Journal homepage: http://ejournal.undip.ac.id/index.php/ksa

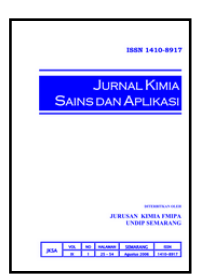

\title{
Modifikasi Zeolit Alam Menggunakan Besi (Fe) dan Kobalt (Co) untuk Katalis Degradasi Fenol
}

\author{
Marina Adriati ${ }^{\mathrm{a}}$, Ahmad Suseno ${ }^{\mathrm{a}^{*}}$, Taslimah $^{\mathrm{a}}$ \\ a Physical Chemistry Laboratory, Chemistry Department, Faculty of Sciences and Mathematics, Diponegoro University, Jalan Prof. \\ Soedarto, Tembalang, Semarang \\ b Inorganic Chemistry Laboratory, Chemistry Department, Faculty of Sciences and Mathematics, Diponegoro University, Jalan Prof. \\ Soedarto, Tembalang, Semarang \\ * Corresponding author: suseno@live.undip.ac.id
}

Article Info

Keywords:

zeolites,

modification, Fe and Co, catalyst, phenol

Kata kunci:

zeolit, modifikasi, Fe dan Co, katalis , fenol

\section{Abstract}

Abundance of natural zeolite in Indonesia is large enough to provide various fields of utilization, which one of them is as a catalyst material. The ability of these zeolite catalysts can be improved through the modification of zeolites by metal impregnation. In this study we conducted a modification of natural zeolites through impregnating of iron (Fe) and cobalt (Co) for catalysts oxidation phenol. Modification of natural zeolites was made through acid leaching stage using $\mathrm{HF}, \mathrm{HCl}$, and $\mathrm{NH}_{4} \mathrm{Cl}$ continued impregnating of metal. Characterization of the products used $\mathrm{x}$-ray diffractometer, surface area analyzer, and catalytic test was carried out on sample. The characterization indicate the mineral composition of the main component of the zeolite is mordenit, total acidity of $\mathrm{Fe}_{2} \mathrm{O}_{3}$-zeolite catalysts obtained at $2.7 \mathrm{mmol} / \mathrm{g}$ and $\mathrm{CoO}$-zeolite catalyst at $2.5 \mathrm{mmol} / \mathrm{g}$, $\mathrm{Fe}_{2} \mathrm{O}_{3}$-zeolite and $\mathrm{CoO}$-zeolite have specific surface area and total pore volume sequentially, that is $38.3918 \mathrm{~m}^{2} / \mathrm{g}, 16.6569 \mathrm{~cm}^{3} / \mathrm{g}$ and $28.6209 \mathrm{~m}^{2} / \mathrm{g}, 12.5072 \mathrm{~cm}^{3} / \mathrm{g}$ and the catalyst can improve the ability of hydrogen peroxide $\left(\mathrm{H}_{2} \mathrm{O}_{2}\right)$ in degrading phenols of $16.93 \%$ at a dose of $5 \mathrm{mg}$ of catalyst, initial phenol concentration of $100 \mathrm{mg} / \mathrm{L}, 20 \mathrm{~mL}$ volume of phenol, and the contact time of 24 hours.

\section{Abstrak}

Kelimpahan zeolit alam di Indonesia cukup besar sehingga memberikan peluang pemanfaatan di berbagai bidang, salah satunya sebagai bahan katalis. Kemampuan katalis zeolit dapat ditimgkatkan melalui modifikasi zeolit dengan pengembanan logam. Pada penelitian ini telah dilakukan modifikasi zeolit alam melalui pengembanan besi (Fe) dan kobalt (Co) untuk katalis oksidasi fenol. Modifikasi zeolit alam dilakukan melalui tahap pencucian asam menggunakan $\mathrm{HF}, \mathrm{HCl}$, dan $\mathrm{NH}_{4} \mathrm{Cl}$ dilanjutkan pengembanan logam. Karakterisasi produk dilakukan menggunakan $\mathrm{x}$-ray diffraktometer, surface area analyzer, dan uji katalitik dilakukan terhadap sampel fenol. Hasil karakterisasi menunjukkan komposisi mineral komponen utama penyusun zeolit adalah mordenit, keasaman total katalis $\mathrm{Fe}_{2} \mathrm{O}_{3}$-zeolit yang diperoleh sebesar 2,7 mmol/g dan katalis $\mathrm{CoO}$-zeolit sebesar 2,5 mmol/g, katalis $\mathrm{Fe}_{2} \mathrm{O}_{3}$-zeolit dan katalis $\mathrm{CoO}$-zeolit memiliki luas permukaan spesifik dan volume pori total secara berurutan, yaitu 38,3918 $\mathrm{m}^{2} / \mathrm{g}, 16,6569 \mathrm{~cm}^{3} / \mathrm{g}$ dan $28,6209 \mathrm{~m}^{2} / \mathrm{g}, 12,5072 \mathrm{~cm}^{3} / \mathrm{g}$ serta katalis mampu meningkatkan kemampuan hidrogen peroksida $\left(\mathrm{H}_{2} \mathrm{O}_{2}\right)$ dalam mendegradasi fenol sebesar $16,93 \%$ pada dosis katalis $5 \mathrm{mg}$, konsentrasi awal fenol $100 \mathrm{mg} / \mathrm{L}$, volume fenol $20 \mathrm{~mL}$, dan waktu kontak 24 jam. 


\section{Pendahuluan}

Perkembangan teknologi yang pesat mendorong pertumbuhan industri-industri baru. Meningkatnya jumlah maupun jenis industri akan menimbulkan konsekuensi baru juga, yakni limbah yang dihasilkan. Fenol merupakan salah satu limbah organik berbahaya [1]. Fenol dapat memberikan efek buruk terhadap lingkungan dan kesehatan manusia, antara lain berupa kerusakkan hati dan ginjal pelemahan detak jantung hingga kematian [2].

Usaha mendegradasi fenol dapat dilakukan dengan mengoksidasi fenol menggunakan katalis berbasis zeolit. Saat ini, sesuai konsep green chemistry penggunaan hidrogen peroksida $\left(\mathrm{H}_{2} \mathrm{O}_{2}\right)$ sebagai oksidan dan $\mathrm{H}_{2} \mathrm{O}$ sebagai pelarut untuk reaksi oksidasi lebih disukai karena tidak berbahaya serta tidak menghasilkan produk samping selain oksigen dan $\mathrm{H}_{2} \mathrm{O}$.

Zeolit adalah kristal aluminasilikat hidrat dengan struktur kerangka tiga dimensi yang tersusun atas tetrahedral $\left(\mathrm{SiO}_{4}\right)^{4^{-}}$dan $\left(\mathrm{AlO}_{4}\right)^{5^{-}}$dengan atom oksigen sebagai penghubungnya. Melimpahnya zeolit alam di Indonesia memberikan peluang menggunakannya sebagai bahan katalis. Penelitian hidrokonversi $n^{-}$ heptane menggunakan katalis $\mathrm{H}-\mathrm{ZSM}-5$ menunjukkan bahwa katalis $\mathrm{H}-\mathrm{ZSM}-5$ dapat digunakan untuk reaksi hydrocracking.

Kemampuan katalis zeolit dapat pula ditingkatkan melalui pengembanan logam. Niaei $d k k$. [3] menyatakan bahwa modifikasi katalis ZSM-5 menggunakan logam transisi menunjukkan aktivitas katalitik pada reaksi konversi senyawa organik volatile menggunakan zeolit berpengemban logam copper (Cu) dan cobalt (Co). Pengembanan logam besi (Fe) dalam silika gel dari sekam padi juga telah dilakukan oleh Adam dkk. [4] untuk oksidasi fenol. Hasil konversi oksidasi fenol mencapai 95,2\% dengan pengembanan logam besi (Fe) sebesar $10 \%$ dari berat silika.

Berdasarkan informasi penelitian-penelitian yang telah dilakukan sebelumnya, maka dalam penelitian ini akan dilakukan modifikasi zeolit alam Bayat kabupaten Klaten melalui pengembanan logam besi (Fe) dan kobaltt (Co) diharapkan akan meningkatkan jumlah situs asam lewis sehingga semakin meningkatkan kemampuan untuk mendegradasi fenol. Karakterisasi untuk dilakukan dengan menentukan komponen mineral menggunakan $X-R D$ ( $X$-Ray Diffraction), menentukan sifat keasaman total katalis menggunakan metode gravimetri, menentukan porositas katalis menggunakan metode BET (Brunauer-Emmet-Teller) surface area analyzer dan uji katalitik terhadap fenol.

\section{Metodologi}

\section{Alat dan Bahan}

Gelas beker, gelas ukur, labu ukur, pengaduk, pipet tetes, botol vial, pengayak ukuran 100 mesh, oven (ARISTON), eksikator, hot plate, pengaduk magnet (magnetic stirrer), kertas indikator $\mathrm{pH}$, kertas saring halus dan whatman 42, neraca analitik. furnace
(VULCAN), difraktometer sinar-X (Shimadzu 6000), surface area analyzer (NOVA 1000 Gas Sorption Analyzer), dan spektrofotometer UV-Visible (Shimadzu UV-Vis Spectrophotometre 1601).

Zeolit alam Bayat (lolos ayakan ukuran 100 mesh) Zeolit alam Bayat (lolos ayakan ukuran 100 mesh), $\mathrm{FeCl}_{3} \cdot 6 \mathrm{H}_{2} \mathrm{O}$ (Merck, p.a.), $\mathrm{Co}\left(\mathrm{NO}_{3}\right)_{2} \cdot 6 \mathrm{H}_{2} \mathrm{O}$ (Merck, p.a.), $\mathrm{HCl} 6 \mathrm{~N}$ (Merck, p.a.), $\mathrm{HF} 1 \%$ (Merck, p.a.), $\mathrm{NH}_{4} \mathrm{Cl}$ (Merck, p.a.), $\mathrm{C}_{6} \mathrm{H}_{5} \mathrm{OH}$ (Merck, p.a.), $\mathrm{H}_{2} \mathrm{O}_{2}$ (Merck, p.a.), 4-aminoantipirin (Merck, p.a.), $\mathrm{NaOH}$ (Merck, p.a.), $\mathrm{K}_{3} \mathrm{Fe}(\mathrm{CN})_{6}$ p.a (Merck, p.a.), gas $\mathrm{N}_{2}$, dan akuades.

\section{Preparasi Sampel Zeolit}

Zeolit alam Bayat Klaten digerus dan diayak hingga lolos ayakan ukuran 100 mesh kemudian dicuci menggunakan akuades. Selanjutnya penyaringan menggunakan kertas saring halus dan dikeringkan dalam oven pada suhu $120^{\circ} \mathrm{C}$ selama 1 jam. Zeolit tersebut kemudian dihaluskan dengan digerus dan disimpan dalam eksikator sehingga diperoleh sampel zeolit alam.

\section{Aktivasi Zeolit Alam}

Sampel zeolit alam yang diperoleh kemudian dilakukan perendaman dalam larutan $\mathrm{HF}$ 1\% dengan pengadukkan selama 1 jam. Zeolit alam kemudian dicuci menggunakan akuades dan dikeringkan dengan oven pada suhu $120^{\circ} \mathrm{C}$ selama 1 jam. Tahap berikutnya zeolit alam digerus hingga halus kembali dan direndam di dalam $\mathrm{HCl} 6 \mathrm{~N}$ selama 4 jam. Kemudian zeolit disaring dan dicuci menggunakan akuades hingga $\mathrm{pH}$ mendekati netral. Selanjutnya zeolit dikeringkan menggunakan oven pada suhu $120^{\circ} \mathrm{C}$ selama 2 jam. Zeolit tersebut kemudian direndam dalam larutan $\mathrm{NH}_{4} \mathrm{Cl} 0,1 \mathrm{~N}$ selama 24 jam dan disimpan dalam eksikator hingga kering. Zeolit yang telah kering dipanaskan pada furnace suhu $400^{\circ} \mathrm{C}$ selama 4 jam dan disimpan kembali dalam eksikator.

\section{Pengembanan Logam Besi (Fe)}

Pengembanan logam besi (Fe) dilakukan dengan merendam bubuk zeolit yang telah diaktifkan dalam larutan $\mathrm{FeCl}_{3} \cdot 6 \mathrm{H}_{2} \mathrm{O}$ selama $24 \mathrm{jam}$. Kemudian campuran tersebut di oven pada suhu $120^{\circ} \mathrm{C}$ dan dikalsinasi pada suhu $550^{\circ} \mathrm{C}$ selama 5 jam.

\section{Pengembanan Logam Kobaltt (Co)}

Pengembanan logam kobaltt (Co) dilakukan dengan merendam bubuk zeolit yang telah diaktifkan dalam larutan $\mathrm{Co}\left(\mathrm{NO}_{3}\right)_{2} \cdot 6 \mathrm{H}_{2} \mathrm{O}$ selama 24 jam. Kemudian campuran tersebut di oven pada suhu $120^{\circ} \mathrm{C}$ dan dikalsinasi pada suhu $550^{\circ} \mathrm{C}$ selama 5 jam.

\section{Krakterisasi Zeolit Termodifikasi}

Karakterisasi zeolit alam setelah pengembanan logam dilakukan dengan menentukan komponen mineral menggunakan $X-R D$ ( $X$-Ray Diffraction), menentukan sifat keasaman total katalis menggunakan metode gravimetri, dan menentukan porositas katalis menggunakan metode BET (Brunauer-Emmet-Teller) surface area analyzer. 


\section{Uji aktivitas Katalitik Katalis}

Uji aktivitas katalitik katalis dilakukan dengan menggunakan gelas beker $50 \mathrm{~mL}$ untuk tempat proses reaksi. Fenol dengan konsentrasi $100 \mathrm{mg} / \mathrm{L}$ sebanyak 20 mL dan hidrogen peroksida $\left(\mathrm{H}_{2} \mathrm{O}_{2}\right) 30 \%$ dimasukkan ke dalam wadah kemudian ditambahkan dengan katalis zeolit termodifikasi sebanyak $5 \mathrm{mg}$. Perbandingan konsentrasi antara fenol: $\mathrm{H}_{2} \mathrm{O}_{2}$ yaitu 1:1. Selanjutnya campuran diaduk perlahan-lahan dengan kondisi operasi pada suhu kamar $25^{\circ} \mathrm{C}$ dan pendiaman selama 24 jam. Perlakuan degradasi fenol yang sama juga dilakukan tetapi tanpa menggunakan katalis. Fenol sisa lalu dianalisis menggunakan spektrofotometer UV-Vis pada panjang gelombang maksimum. Analisis fenol sisa menggunakan reagen 4-aminoantipirin (4-AAP) 2\% dan $\mathrm{K}_{3} \mathrm{Fe}(\mathrm{CN})_{6} 8 \%$ dalam kondisi basa dengan $\mathrm{pH} 10 \pm 2$.

\section{Hasil dan Pembahasan}

\section{Preparasi Sampel Zeolit}

Preparasi sampel dilakukan dengan penggerusan yang bertujuan untuk meningkatkan luas permukaan zeolit. Selanjutnya zeolit diayak hingga lolos ayakan 100 mesh dan dicuci menggunakan akuades serta dikeringkan pada suhu $120^{\circ} \mathrm{C}$. Pencucian menggunakan akuades bertujuan untuk meminimalisasi komponenkomponen pengotor yang dapat larut dalam air. Pengeringan pada suhu $120^{\circ} \mathrm{C}$ bertujuan untuk menghilangkan molekul air yang terperangkap secara bebas pada zeolit alam.

\section{Aktivasi Zeolit Alam}

Zeolit alam pada umumnya memiliki ukuran pori tidak seragam, aktivitas katalitik yang rendah dan mengandung banyak pengotor. Oleh karena itu, sebelum digunakan sebagai pengemban logam, zeolit alam perlu diaktifkan terlebih dahulu. Sampel zeolit yang telah diperoleh selanjutnya diaktifkan dengan perlakuan awal yaitu perendaman ke dalam $\mathrm{HF} 1 \%$ bertujuan untuk melepaskan pengotor $\mathrm{SiO}_{2}$ dalam bentuk amorf yang berada dalam sampel zeolit. Perendaman dalam $\mathrm{HCl}$ bertujuan untuk menghilangkan oksida-oksida bebas dari logam-logam seperti $\mathrm{Mg}, \mathrm{Al}$, Fe dan Ca yang ada pada sampel zeolit. Selanjutnya pencucian menggunakan akuades hingga $\mathrm{pH}$ mendekati netral. Pengovenan zeolit pada suhu $120^{\circ} \mathrm{C}$ di maksudkan untuk menguapkan molekul air yang terperangkap secara bebas dalam zeolit. Zeolit selanjutnya direndam dalam garam $\mathrm{NH}_{4} \mathrm{Cl}$ yang bertujuan untuk mengoptimalkan pertukaran kation. Proses yang terjadi dalam pertukaran kation, diharapkan kation alkali atau alkali tanah yang masih ada pada zeolit disubstitusikan dengan kation $\mathrm{NH}_{4}{ }^{+}$sehingga terbentuk $\mathrm{NH}_{4}$-zeolit. Setelah diperoleh $\mathrm{NH}_{4}$-zeolit kemudian pemanasan pada suhu $400^{\circ} \mathrm{C}$ selama 4 jam yang bertujuan untuk membentuk $\mathrm{H}-$ zeolit disertai dengan penguapan gas $\mathrm{NH}_{3}$.

\section{Pengembanan Logam Besi (Fe) dan Kobalt (Co)}

Pengembanan logam besi (Fe) dan kobalt (Co) dilakukan dengan merendam zeolit alam hasil aktivasi ke dalam larutan logam prekusor. Pengembanan besi (Fe) dilakukan dengan perendaman zeolit teraktivasi ke dalam larutan $\mathrm{FeCl}_{3} \cdot 6 \mathrm{H}_{2} \mathrm{O}$ selama 24 jam. Selanjutnya, untuk pengembanan logam kobal (Co) dilakukan dengan perendaman zeolit teraktivasi ke dalam larutan $\mathrm{Co}\left(\mathrm{NO}_{3}\right)_{2} \cdot 6 \mathrm{H}_{2} \mathrm{O}$ selama 24 jam. Perendaman selama 24 jam bertujuan agar proses pengembanan logam ke dalam zeolit diharapkan maksimal. Setelah itu, dilakukan pengovenan pada suhu $120^{\circ} \mathrm{C}$ bertujuan untuk menguapkan air yang merupakan pelarut dari logam prekusor. Zeolit yang telah kering tersebut lalu dikalsinasi pada suhu $550^{\circ} \mathrm{C}$ selama 5 jam. Tujuan kalsinasi adalah untuk membentuk oksida logam baik itu besi (Fe) maupun kobal (Co), menguapkan pengotorpengotor organik, dan memperbesar permukaan pengemban.

\section{Karakterisasi Menggunakan Difraktometer Sinar-X (X-RD)}

Karakterisasi menggunakan difraktometer sinar-X (X-RD) dilakukan untuk mengetahui perubahan pola difraktogram zeolit alam sebelum dan sesudah perlakuan. Difraktogram zeolit hasil perlakuan ditunjukkan pada Gambar 1.

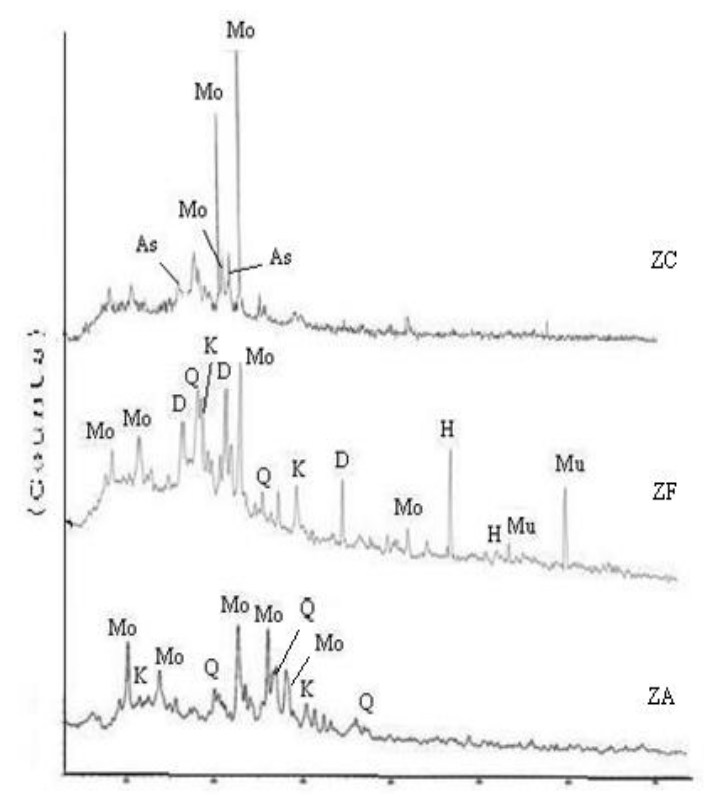

Gambar 1. Difraktogram zeolit alam, katalis zeolit berpengemban logam besi dan berpengemban logam kobalt

Interpretasi ini menunjukkan bahwa zeolit alam yang telah dilakukan pengembanan logam besi (Fe) mengandung mineral mordenit, mullit, donbassit, kuarsa dan klinoptillolit. Perlakuan pengembanan logam besi $(\mathrm{Fe})$ ke dalam zeolit menghasilkan terbentuknya oksida logam berupa kristal $\mathrm{Fe}_{2} \mathrm{O}_{3}$ (hematit). Terbentuknya kristal $\mathrm{Fe}_{2} \mathrm{O}_{3}$ (hematit) ini dibuktikan dengan munculnya puncak difraksi $2 \theta$ $57,4784^{\circ} ; 63,9200^{\circ}$ dan $80,7816^{\circ}$. Berdasarkan data JCPDS-ICDD 1997 nomor 33-0664 puncak-puncak tersebut merupakan puncak spesifik dari kristal $\mathrm{Fe}_{2} \mathrm{O}_{3}$ (hematit).

Difraktogram katalis zeolit berpengemban logam kobal (Co) di atas menunjukkan puncak dari mordenit dan aluminum silikat. Sedangkan puncak difraksi 
klinoptillolit dan kuarsa pada zeolit berpengemban logam kobal (Co) tidak muncul hal ini dimungkinkan karena klinoptillolit dan kuarsa larut dalam asam nitrat encer yang berasal dari larutan logam prekursor $\mathrm{Co}\left(\mathrm{NO}_{3}\right)_{2} \cdot 6 \mathrm{H}_{2} \mathrm{O}$. Berdasarkan data JCPDS-ICDD 1997 nomor 43-1004 puncak difraksi pada sudut $2 \theta \quad 42,401^{\circ}$; $36,503^{\circ}$ dan $61,520^{\circ}$ merupakan puncak spesifik dari $\mathrm{CoO}$ akan tetapi pada difraktogram zeolit berpengemban logam kobal (Co) tidak menunjukkan puncak spesifik dari oksida logam kobal (Co) tersebut. Kemungkinan kristal oksida kobal (CoO) terbentuk namun kristalinitasnya sangat rendah atau mendekati amorf sehingga tidak terbaca puncak difraksinya.

\section{Uji Sifat Asam}

Keasaman padatan yang ditentukan dalam penelitian ini adalah keasaman total. Keasaman total diperoleh melalui pengukuran jumlah milimol basa amoniak dari fasa gas yang diadsorpsi oleh permukaan padatan ekuivalen dengan jumlah asam pada permukaan padatan yang menyerap basa tersebut. Uji keasaman ini dilakukan untuk mengetahui banyaknya situs asam total dalam katalis.

Tabel 1: Total situs asam katalis

\begin{tabular}{ccc}
\hline $\begin{array}{c}\text { Sampel } \\
\text { katalis }\end{array}$ & $\begin{array}{c}\text { Selisih massa } \\
(\mathrm{g})\end{array}$ & $\begin{array}{c}\text { Total situs } \\
\text { asam } \\
(\mathrm{mmol} / \mathrm{g})\end{array}$ \\
\hline $\begin{array}{c}\text { Zeolit aktif } \\
\mathrm{Fe}_{2} \mathrm{O}_{3}-\end{array}$ & 0,0036 & 0,4 \\
$\begin{array}{c}\text { zeolit } \\
\mathrm{CoO}-\text { zeolit }\end{array}$ & 0.0231 & 2,7 \\
\hline
\end{tabular}

Hasil karakterisasi keasaman padatan menunjukkan peningkatan keasaman katalis total dibandingkan dengan zeolit aktif. Total situs asam katalis $\mathrm{Fe}_{2} \mathrm{O}_{3}$-zeolit meningkat sebesar 2,3 mmol/g dan CoO-zeolit sebesar 2,1 $\mathrm{mmol} / \mathrm{g}$. Meningkatnya keasaman total katalis karena adanya perlakuan kalsinasi dan pengembanan logam pada zeolit. Kalsinasi pada suhu tinggi dengan gas nitrogen dapat menghilangkan pengotor yang menutupi pori-pori zeolit sehingga pori zeolit menjadi lebih terbuka dan permukaan padatan katalis semakin bersih. Selanjutnya, perlakuan pengembanan logam besi (Fe) dan kobal (Co) pada zeolit juga menyebabkan meningkatnya keasaman total padatan katalis. Sispersi logam aktif ke permukaan pengemban memperluas permukaan katalis dan memperbanyak situs aktif katalis. Meningkatnya keasaman total katalis akibat pengembanan logam dikarenakan logam besi (Fe) dan kobal (Co) merupakan unsur golongan transisi yang menyediakan orbital $d$ yang belum terisi penuh oleh elektron.

\section{Karakterisasi Menggunakan Metode BET (Brunauer- Emmet-Teller) Surface Area Analyzer}

Metode BET (Brunauer-Emmet-Teller) surface area analyzer digunakan untuk menentukan ukuran pori, volume pori, dan luas permukaan katalis. Pada penelitian ini yang dikarakterisasi menggunakan metode BET (Brunauer-Emmet-Teller) surface area analyzer adalah katalis $\mathrm{Fe}_{2} \mathrm{O}_{3}$-zeolit dan katalis $\mathrm{CoO}-$ zeolit. Analisis ini bertujuan untuk membandingkan porositas dari kedua katalis tersebut. Klasifikasi ukuran pori menurut IUPAC dalam Weitkamp dan Puppe [5] yaitu, mikropori $\left(\mathrm{d}_{\mathrm{p}} \leq 2 \mathrm{~nm}\right)$, mesopori ( $2 \mathrm{~nm}<\mathrm{d}_{\mathrm{p}} \leq 50$ $\mathrm{nm})$, dan makropori ( $\left.\mathrm{d}_{\mathrm{p}}>50 \mathrm{~nm}\right)$.

Tabel 2: Hasil nilai radius pori rata-rata, luas permukaan spesifik, dan volume total pori sampel katalis $\mathrm{Fe}_{2} \mathrm{O}_{3}$-zeolit serta CoO-zeolit

\begin{tabular}{cccc}
\hline $\begin{array}{c}\text { Sampel } \\
\text { katalis }\end{array}$ & $\begin{array}{c}\text { Radius Pori } \\
\text { Rata-Rata } \\
(\AA)\end{array}$ & $\begin{array}{c}\text { Luas } \\
\text { Permukaan } \\
\text { Spesifik } \\
\left(\mathrm{m}^{2} / \mathrm{g}\right)\end{array}$ & $\begin{array}{c}\text { Volume } \\
\text { Total Pori } \\
\left(\mathrm{cm}^{3} / \mathrm{g}\right)\end{array}$ \\
\hline $\begin{array}{c}\mathrm{Fe}_{2} \mathrm{O}_{3}- \\
\text { zeolit }\end{array}$ & 13,403 & 38,3918 & 16,6569 \\
$\begin{array}{c}\mathrm{CoO}- \\
\text { zeolit }\end{array}$ & 13,500 & 28,6209 & 12,5072 \\
\hline
\end{tabular}

Data pada Table 2 terlihat bahwa ukuran pori katalis $\mathrm{Fe}_{2} \mathrm{O}_{3}$-zeolit dan $\mathrm{CoO}$-zeolit termasuk dalam mikropori $\left(\mathrm{d}_{\mathrm{p}} \leq 2 \mathrm{~nm}\right)$. Katalis CoO-zeolit memiliki volume total pori dan luas permukaan spesifik yang lebih rendah dibandingkan katalis $\mathrm{Fe}_{2} \mathrm{O}_{3}$-zeolit, hal ini dimungkinkan proses kalsinasi yang terjadi belum maksimal. Selain itu, rendahnya luas permukaan spesifik dan volume pori total katalis $\mathrm{CoO}$-zeolit dimungkinkan karena terjadi penumpukkan oksida kobal (Co) pada pori zeolit sehingga menutupi pori-pori zeolit.

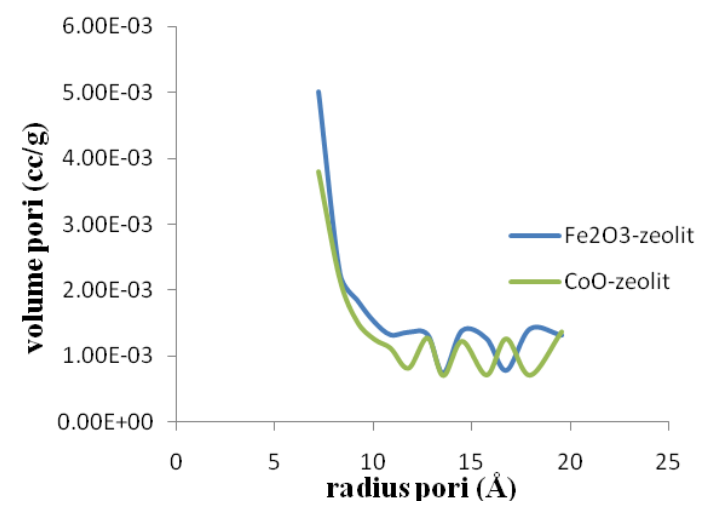

Gambar 2. Grafik pola hubungan volume pori katalis $\mathrm{Fe}_{2} \mathrm{O}_{3}$-zeolit dan $\mathrm{CoO}$-zeolit terhadap radius pori

\section{Uji aktivitas Katalitik Katalis}

Uji aktivitas katalitik katalis $\mathrm{Fe}_{2} \mathrm{O}_{3}$-zeolit dan $\mathrm{CoO}-$ zeolit dilakukan terhadap sampel fenol. Oksidasi fenol dilakukan dengan memasukkan katalis sebanyak $5 \mathrm{mg}$ ke dalam fenol $100 \mathrm{mg} / \mathrm{L}$ dan ditambahkan dengan hidrogen peroksida $\left(\mathrm{H}_{2} \mathrm{O}_{2}\right) \quad 30 \%$. Perbandingan konsentrasi fenol: $\mathrm{H}_{2} \mathrm{O}_{2}$ yang digunakan yaitu 1:1. Hidrogen peroksida $\left(\mathrm{H}_{2} \mathrm{O}_{2}\right)$ ini berfungsi sebagai agen pengoksidasi. Aktivitas katalitik katalis terlihat dengan membandingkan proses oksidasi tanpa menggunakan katalis dan proses oksidasi yang menggunakan katalis selama 24 jam seperti yang terlihat dalam Tabel 4 . 
Tabel 3: Aktivitas Katalitik Katalis

\begin{tabular}{|c|c|}
\hline Sampel & $\begin{array}{l}\text { Konsentrasi Fenol } \\
\text { Sisa }\end{array}$ \\
\hline Fenol $+\mathrm{H}_{2} \mathrm{O}_{2}$ & $16,93 \mathrm{mg} / \mathrm{L}$ \\
\hline $\begin{array}{c}\text { Fenol }+\mathrm{H}_{2} \mathrm{O}_{2}+\text { katalis } \mathrm{Fe}_{2} \mathrm{O}_{3}- \\
\text { zeolit }\end{array}$ & $0 \mathrm{mg} / \mathrm{L}$ \\
\hline $\begin{array}{c}\text { Fenol }+\mathrm{H}_{2} \mathrm{O}_{2}+\text { katalis } \mathrm{CoO}- \\
\text { zeolit }\end{array}$ & $0 \mathrm{mg} / \mathrm{L}$ \\
\hline
\end{tabular}

Hasil yang diperoleh menunjukkan bahwa oksidasi fenol tanpa katalis menghasilkan fenol sisa sebesar $16,93 \mathrm{mg} / \mathrm{L}$ dengan kemampuan oksidasi sebesar $83,07 \%$. Sedangkan, pada proses oksidasi fenol menggunakan katalis tidak ada fenol sisa baik itu yang menggunakan katalis $\mathrm{Fe}_{2} \mathrm{O}_{3}$-zeolit maupun $\mathrm{CoO}$-zeolit, dengan demikian kemampuan degradasi fenol menggunakan katalis meningkat dibandingkan tanpa menggunakan katalis menjadi $100 \%$. Penggunaan katalis $\mathrm{Fe}_{2} \mathrm{O}_{3}$-zeolit dan katalis $\mathrm{CoO}$-zeolit mampu meningkatkan efektivitas reaksi degradasi fenol dengan $\mathrm{H}_{2} \mathrm{O}_{2}$. Katalis $\mathrm{Fe}_{2} \mathrm{O}_{3}$-zeolit dan CoO-zeolit bekerja dengan menyediakan situs asam baik itu asam Bronsted maupun asam Lewis.

\section{Kesimpulan}

Telah diperoleh katalis $\mathrm{Fe}_{2} \mathrm{O}_{3}$-zeolit dan $\mathrm{CoO}$-zeolit melalui pengembanan logam besi (Fe) dan kobal (Co) pada zeolit alam. Komposisi mineral komponen utama penyusun zeolit adalah mordenit, keasaman total katalis $\mathrm{Fe}_{2} \mathrm{O}_{3}$-zeolit yang diperoleh sebesar $2,7 \mathrm{mmol} / \mathrm{g}$ dan katalis $\mathrm{CoO}$-zeolit sebesar 2,5 mmol/g, katalis $\mathrm{Fe}_{2} \mathrm{O}_{3}$ zeolit dan katalis CoO-zeolit memiliki luas permukaan spesifik dan volume pori total secara berurutan, yaitu $38,3918 \mathrm{~m}^{2} / \mathrm{g}, 16,6569 \mathrm{~cm}^{3} / \mathrm{g}$ dan $28,6209 \mathrm{~m}^{2} / \mathrm{g}, 12,5072$ $\mathrm{cm}^{3} / \mathrm{g}$. Katalis yang dibuat mampu meningkatkan kemampuan hidrogen peroksida $\left(\mathrm{H}_{2} \mathrm{O}_{2}\right)$ dalam mendegradasi fenol sebesar $16,93 \%$ pada dosis katalis 5 $\mathrm{mg}$, konsentrasi awal fenol $100 \mathrm{mg} / \mathrm{L}$, volume fenol 20 $\mathrm{mL}$, dan waktu kontak 24 jam.

\section{Daftar Pustaka}

[1] Rey-May Liou, Shih-Hsiung Chen, CuO impregnated activated carbon for catalytic wet peroxide oxidation of phenol, Journal of Hazardous Materials, 172, 1, (2009) http://dx.doi.org/10.1016/j.jhazmat.2009.07.012

[2] R Arbianti, Pengolahan Limbah Organik (Fenol) Dan Logam Berat (Cr6+ Atau Pt4+) Secara Simultan Dengan Fotokatalis Tio2, Zno-tio2, Dan Cds-tio2 1. Pendahuluan, Makara Journal of Technology, 9, 2, (2005)

[3] Aligholi Niaei, Dariush Salari, Seyed Ali Hosseini, Study of catalytic activities of nanostructure copper and cobalt supported ZSM-5 catalysts for conversion of volatile organic compounds, Turkish Journal of Chemistry, 34, 1, (2010) 15-26

[4] Farook Adam, Jeyashelly Andas, Ismail Ab Rahman, A study on the oxidation of phenol by heterogeneous iron silica catalyst, Chemical Engineering Journal, 165, $\begin{array}{lr}2, & \text { (2010) }\end{array}$ http://dx.doi.org/10.1016/j.cej.2010.09.054
[5] Jens Weitkamp, Lothar Puppe, Catalysis and Zeolites: Fundamentals and Applications, Springer-Verlag Berlin Heidelberg, Berlin, 1999. 